\title{
O ensino de cinemática apoiado na metodologia peer instruction para alunos de eja
}

\author{
Teaching kinematics based on the peer instruction methodology for EJA \\ students
}

\section{Ronildo De ANDrade RAMALHO*}

Mestrado Profissional no Ensino de Física Departamento Física, Universidade Federal do Amazonas. Av. General Rodrigo Octavio Jordão Ramos, 1200 - Coroado I, Manaus - AM, 69067-005. Instituto Federal do Amazonas. Av. Sete de Setembro, 1975 - Centro, Manaus AM, 69020-120

\begin{abstract}
Resumo
O estudo da Física tem enfrentado grandes desafios na sociedade, em particular relativos ao seu âmbito conceitual. O ensino dessa disciplina na Educação de Jovens e Adultos (EJA) apresenta desafio ainda maior do que o ensino regular, dado que as turmas têm faixas etárias divergentes, alunos que não entram em sala de aula há mais de 20 anos, dentre outras situações que tendem a sufocar o ensino na EJA. Devido a essa diversidade de experiências, pessoal e profissional, de cada discente, optou-se em adotar um método que privilegiasse conceitos de Física e cinemática básica, em que o aluno pudesse ser visto como figura ativa na aprendizagem. Em virtude de essa abordagem ser mais conceitual do que matemática, foi utilizada, nesta pesquisa, a metodologia Peer Instruction (PI) do professor Eric Mazur, que trabalha principalmente com questões conceituais e interação entre grupos ou pares. A aplicação da referida metodologia se baseou no desenvolvimento de atividades de leitura que visavam desenvolver o entendimento dos conceitos a serem abordados em questões conceituais. Em razão dessa metodologia específica, o estudante de EJA foi capaz de compreender as noções fundamentais da cinemática e realizar operações matemáticas simples. O desenvolvimento da metodologia ocorreu em duas turmas de primeiro ano do ensino médio da EJA, e os resultados foram comparados com uma turma de primeiro ano do ensino médio em que não houve a adoção da metodologia PI. A análise dos resultados deu-se a partir do estudo dos ganhos normalizados de Hake. Esses dados foram comparados a outras literaturas no âmbito nacional e internacional.
\end{abstract}

Palavras-chave: Ensino de Física. Peer Instrutction. Ensino Conceitual. Aprendizagem Ativa.

\footnotetext{
*ro_nildo@hotmail.com
} 


\begin{abstract}
The study of physics has faced major challenges in society, mainly related to its conceptualization. Teaching this subject in Youth and education Adult (EJA) presents an even greater setback than regular education, given that the classes have divergent age groups, students who distant from a classroom for more than 20 years, among other situations that tend to stifle teaching in EJA. Due to this diversity of experiences, personal and professional, it was decided to apply a method mainly based on concepts of physics and basic kinematics, in which the student could be seen as an active figure in learning. Because this approach is more conceptual than mathematical, we used Professor Eric Mazur's Peer Instruction (PI) methodology, which deals mainly with conceptual issues and interaction between groups or peers. The application of this methodology had as aid the development of reading activities that aimed to collaborate the understanding of the concepts to be approached in conceptual questions. When applied, the EJA student, because of this specific methodology, was able to understand the fundamental notions of kinematics and to perform simple mathematical operations. The methodology development took place in two first year high school classes of the EJA, and the results were compared with a first year high school class in which there the PI methodology was not adopted. The analysis of the results was based on the study of Hake's normalized earnings. Moreover, these data were compared to other national and international literature.
\end{abstract}

Keywords: Teaching Physics. Peer Instrutction. Conceptual Teaching. Active Learning.

\title{
I. INTRODUÇÃO
}

O ensino de Física está repleto de oportunidades desafiadoras que surgem como estímulo para a busca de soluções didáticas. Esse fato não é privilégio do ensino fundamental, médio, superior, ensino regular ou Educação de Jovens e Adultos (EJA). A forma tradicional de ensinar muitas vezes é empregada como um monólogo, em que o aluno, no papel de ouvinte, tenta aprender ou memorizar tudo que é abordado em sala de aula, proporciona satisfação parcial na aprendizagem dessa ciência.

Esse tradicionalismo não permite que o aluno compreenda completamente o conteúdo ministrado, deixando uma lacuna no ensino de conceitos importantes dessa disciplina. Além disso, o grande número de alunos de EJA, por exemplo, que abandonam a escola por não lograrem êxito na assimilação do conteúdo foi apontado como uma das justificativas para construir aulas mais dinâmicas.

É importante conduzir aulas de Física para alunos da EJA de forma diferenciada. Não se pode planejar na EJA da mesma forma que são idealizadas as aulas para o ensino regular. Para Arroyo (2007), Currículos de EJA devem ser construídos de forma que articulem a vida concreta do sujeito, e suas especificidades devem ser levadas em consideração.

Desse modo, é importante colocar o aluno como componente ativo no ensino, ou seja, o mesmo, junto com os colegas, deve participar diretamente da construção do conhecimento. Explorar o conhecimento empírico dos alunos e fazê-los utilizá-los nas teorias abordadas é 
importante pois. ao trabalhar com problemas práticos envolvendo teorias, raciocínio lógico e matemática, os discentes realizarão as atividades de uma maneira mais produtiva.

Aulas tradicionais de Física conservam, como uma de suas principais características, a solução de problemas de todos os níveis. Para alunos de EJA isso não tem sido diferente. Tem-se mostrado a necessidade em resolver problemas e exercícios dos mais variados conteúdos, problemas esses que são chamados por Eric Mazur, em seu livro Peer Instruction: A Users Manual, de computacionais,que utilizam um algoritmo lógico na solução de questões.

A EJA não só tem um caráter social muito importante, mas também traz a oportunidade de levar o estudante a compreender fenômenos que estão por de trás de cálculos e a praticar sua curiosidade intelectual. Compreender um fenômeno da natureza é tão importante quanto realizar um cálculo em um problema de Física.

Destarte, a metodologia Peer Instruction, com abordagem de problemas que enfatizam conceitos de Física, torna-se a forma ideal de ensino, principalmente para o aluno de EJA, dado que o tempo de estudos que esse perfil de aluno possui é reduzido. A abordagem conceitual é uma alternativa interessante que pode resultar em resultados expressivos no ensino de Física para EJA.

A partir disso, surge como proposta uma metodologia baseada no Peer Instruction (PI) do professor de Harvard Eric Mazur, que trabalha tanto o conhecimento empírico do aluno, como também a interação entre pares ou grupos de alunos, e que pode ser alinhada com tarefas de leitura, como sugerido por Mazur em seu livro. Tal interação é proposta pelo professor com base na utilização de livros, apostilas ou material de leitura.

\section{PEER INSTRUCTION E TAREFA DE LEITURA}

Um dos principais problemas que envolvem o ensino de Física é a apresentação do conteúdo que, na maior parte das vezes, é exposto de forma tradicional. Conteúdo que é apenas retirado de um livro de Física e reproduzido ao estudante. Segundo Mazur (2015, p. 26), O problema é a apresentação tradicional do conteúdo, que consiste quase sempre em um monólogo diante de uma plateia passiva. Esse tipo de aula, reiteradamente, leva o estudante a pensar nessa área de conhecimento apenas como relativa à resolução de problemas, de modo a solicitar sempre mais exemplos resolvidos. Entretanto, qual a finalidade de compreender um algoritmo de solução de problemas uma vez que não se possui um entendimento razoável dos conceitos de Física envolvidos? Tendo em vista que o enfoque deste estudo é acerca do ensino da Física, torna-se necessário levar em consideração a relevância da compreensão dos conceitos básicos, que têm a finalidade de auxiliar na resolução de problemas cotidianamente.

Devido à importância de aplicações conceituais da Física e uma abordagem diferenciada do ensino dela, o professor Eric Mazur, após anos de ensino tradicional, criou uma metodologia que trata o aluno como figura ativa no ensino aprendizagem. Essa metodologia passou a ser conhecida como Peer Instruction ou Instrução Pelos Colegas (IpC). 


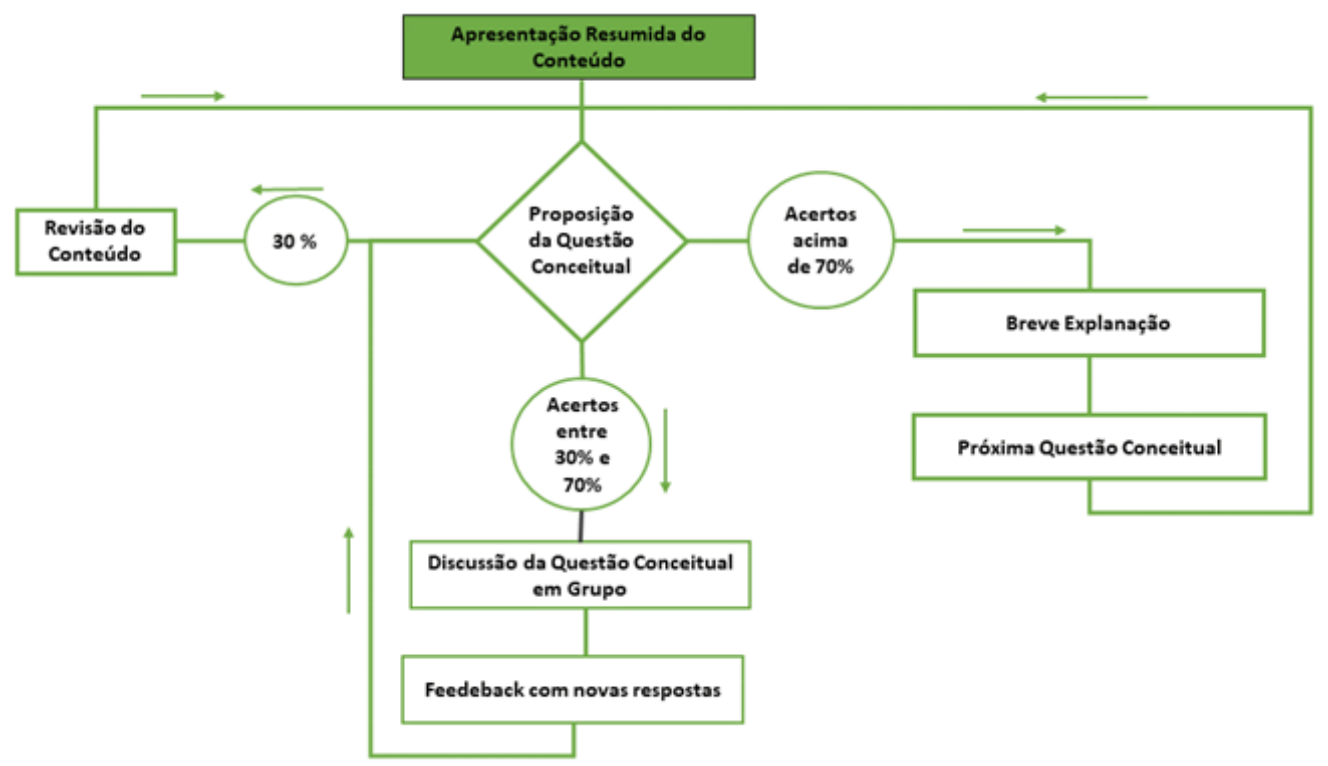

Figura 1: Fluxograma Peer Instruction (Mazur, 1997). Fonte: Própria do autor (2019).

\section{II.1. Aplicação do peer instruction}

A IpC consiste em uma metodologia baseada em questões conceituais e interação entre os alunos. Segundo Mazur (2015, p. 27), a IpC explora a interação entre os estudantes durante as aulas expositivas e foca a atenção dos estudantes nos conceitos que servem de fundamento. Desse modo, as aulas não devem ser em formatos tradicionais, fazendo com que os estudantes assistam aulas teóricas e, após isso, resolvam vários exercícios do assunto abordado.

Nessa metodologia, as tarefas de leitura têm papel importante durante a aplicação da IpC. O conteúdo, repleto de detalhes, deve ser lido e estudado pelos alunos em materiais de apoio, como livros ou apostilas. Não há, portanto, uma aula expositiva. Entretanto, no início de cada aula, um resumo do conteúdo é apresentado com os pontos mais importantes. A sequência de aplicação da IpC deve ser realizada seguindo as etapas apresentadas na Figura 1.

Para Mazur (2015, p. 27), esse processo (a) força os estudantes a pensar com base nos argumentos que estão sendo desenvolvidos e (b) dá-lhes (o professor incluído) um modo de avaliar a sua compreensão do conceito. A metodologia é aplicada da seguinte forma:

a) Apresentação resumida do conteúdo: essa apresentação não deve ocorrer durante um período muito grande da aula, um resumo apresentando os principais e mais importantes conceitos, com no máximo 10 minutos de apresentação, já deve ser suficiente para iniciar a aula;

b) Proposição da questão conceitual: Após a apresentação resumida dos conceitos, aplica-se a questão conceitual. Na primeira realização das questões conceituais os estudantes devem responder de forma individual, e então deve ser observado o nível de acertos da turma, como mostrado a seguir: 
I. Se, menos de $30 \%$ acertar a questão conceitual, aplica-se uma revisão do conceito abordado, seguido da reaplicação do mesmo teste conceitual;

II. Caso o número de acertos esteja entre 30\% e 70\%, a turma se reúne em grupos que discutirão a respeito da questão conceitual e na sequência, reaplica-se a questão;

III. Para um número de acertos maior que $70 \%$ o professor faz uma breve explanação a respeito da questão conceitual discutindo a respeito da resposta que a turma julga correta.

\section{II.2. Leitura antes da aula}

A metodologia IpC, como já foi observado, trata o aluno como agente ativo na aprendizagem. Portanto, é de grande importância que o estudante possua atividades de leituras frequentes. Para que isso ocorra, cabe ao professor implementar o Just It Time Teaching ${ }^{1}$, ou aplicar testes de leitura, como recomendado pelo Professor Eric Mazur. Neste caso, a distribuição de um cronograma de testes de leitura e a aplicação rotineira do mesmo faz-se bastante necessária, e pode otimizar os resultados durante a realização das questões conceituais.

É importante observar que o teste de leitura não deve avaliar os alunos de forma rigorosa, com perguntas e questões complexas. Além disso, deve haver colaboração entre os colegas, dando à avaliação uma dimensão formativa.

\section{TeCNOLOGIAS DA INFORMAÇÃo E COMUNICAÇÃo}

A metodologia IpC demanda eficiência e rapidez na abordagem dos testes conceituais, ou seja, o professor deve dispor do resultado de cada teste de forma instantânea, de modo a permitir uma análise em tempo real dos resultados, viabilizando que o mesmo possa escolher qual, ou quais, sequências didáticas devem sobrevir.

A partir de situações como essa e também outras dificuldades encontradas na correção de questões conceituais ou pré/pós-testes, verificou-se a necessidade de, a partir de Tecnologias da Informação e Comunicação (TICt's), agilizar o processo de obtenção de resultados. A seguir são apresentados os softwares que auxiliaram o desenvolvimento deste trabalho.

\section{III.1. Plickers}

O Plickers é uma ferramenta que se encontra disponível para Android, iOS e também na web pelo site https://www.plickers.com. Basicamente, trata-se de um software que administra a aplicação de testes e avalia em tempo real as respostas dos alunos. O emprego do Plickers se dá a partir de cards, os quais estão disponíveis no site supracitado.

Os dados coletados a partir das respostas da turma são armazenados no site e podem ser extraídos em planilhas do Excel e posteriormente gerar gráficos para análise. Além disso, o aplicativo para smartphones é gratuito e de fácil utilização.

\footnotetext{
${ }^{1} \mathrm{Na}$ aplicação do JiTT, o professor estrutura suas aulas a partir das concepções prévias levantadas em atividades realizadas pelos alunos, em momento anterior a aula. (Araujo et al, 2017, p. 5)
} 


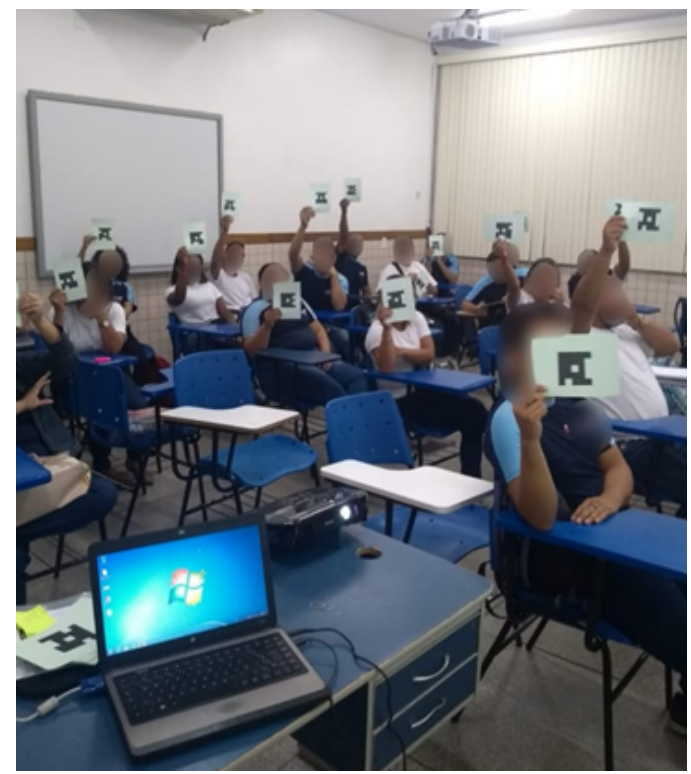

Figura 2: Plickers efetivando a leitura das respostas através dos cards. Fonte: Própria do autor (2019).

\section{III.2. Gradepen}

Para esta pesquisa, foi muito importante analisar os ganhos referentes à metodologia utilizada, fato que requer a aplicação de pré/pós-testes. Todavia, a correção desse tipo de avaliação pode demandar muito tempo, dependendo da quantidade de alunos envolvidos na pesquisa. Devido a isso, para auxiliar o desenvolvimento das questões mencionadas acima, optou-se por utilizar uma ferramenta disponível para Android, iOS e na web a partir do site https:/ / www.gradepen.com/, intitulada GRADEPEN. Com o auxílio deste aplicativo e por meio do site, o docente poderá:

- elaborar avaliações personalizadas;

- criar questões discursivas ou objetivas,

- criar uma prova diferente para cada aluno;

- corrigir provas com maior rapidez;

Esse aplicativo permitiu a formulação dos pré e pós-testes e auxiliou na correção dos mesmos a partir de cartões respostas, de modo que esse processo ganhou celeridade e permitiu agregar os resultados em planilhas no Excel, detalhe muito importante para a análise dos resultados.

\section{Metodologia da Pesquisa}

\section{IV.1. Local e ambiente de aplicação}

A pesquisa à qual se refere este artigo foi desenvolvida e aplicada em uma escola particular situada em Manaus - Amazonas. A escola funciona no período vespertino e 


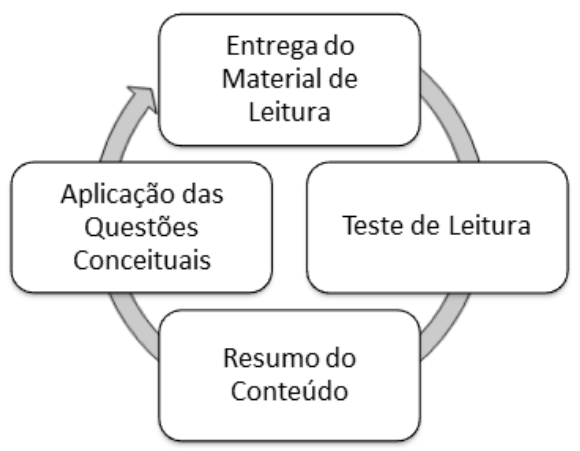

Figura 3: Sequência didática da Metodologia PI. Fonte: Própria do autor (2019).

noturno, atendendo ao Ensino de Jovens e Adultos de primeiro e segundo segmento e Ensino Médio. As propostas pedagógicas da escola contemplam a EJA no ensino presencial e a distância.

\section{IV.2. Procedimentos utilizados}

Para participar dessa pesquisa, foram selecionados, no total, 57 alunos, distribuídos entre 3 turmas de 1a fase do ensino médio. $\mathrm{O}$ andamento da metodologia IpC ocorreu em duas turmas que totalizavam 41 alunos, que foram denominadas turmas $P_{1}$ e $P_{2}$. A execução da metodologia IpC se deu em aulas de 50 minutos cada, e uma aula por semana no período noturno.

Para que o desempenho das turmas fosse comparado, foram selecionados 16 alunos em uma turma de 1a fase do Ensino Médio, para os quais foram aplicadas metodologias tradicionais por meio de aulas expositivas. A turma, dentro desse contexto, foi denominada $T_{1}$ e assim como com as turmas $P_{1}$ e $P_{2}$, as aulas tinham duração de 50 minutos, uma vez por semana.

A escola não possui suporte para a utilização de Clickers. Portanto, foi necessário encontrar uma forma de automatizar a aplicação da metodologia PI. Devido a essa preocupação, optou-se por utilizar o aplicativo Plickers, que se trata de um leitor de cartões impressos pelo professor que possibilita a verificação de respostas instantaneamente. Além da análise das questões conceituais, que ocorreu com o auxílio do Plickers, para comparar os ganhos referentes aos pré e pós-testes, utilizou-se o aplicativo Gradepen, que viabilizou a correção de pré e pós-testes automatizando e proporcionando a redução no tempo de correção dos mesmos e uma melhor análise dos resultados, construção de gráficos e organização dos dados.

$\mathrm{O}$ andamento das aulas utilizando a metodologia IpC ocorreu da forma esquematizada na figura 1 e figura 3, que apresentam a estrutura básica da metodologia. Ela consiste na distribuição antecipada de material de leitura, aplicação de testes de leitura, seguidos de questões conceituais que eram expostas a partir de um aparelho de projeção, e a partir do site www.plickers.com.

As questões conceituais consistiam, em sua maioria, em problemas de vestibulares ou livros. Na apresentação das questões, os alunos dispunham de 2 a 3 minutos para pensar na resposta; em seguida apresentavam suas respostas individuais, a partir dos cartões 
impressos. Com base nos resultados obtidos pela turma, o professor faria a escolha da próxima etapa, que seria de acordo com o que está apresentado na metodologia IpC.

Além dos softwares e aplicativos descritos na seção 3 deste artigo, que auxiliaram nessa pesquisa, a cada aula era utilizado o material descrito abaixo:

- projetor;

- notebook;

- smartphone;

- cartões impressos;

- quadro branco e pincéis;

O conteúdo abordado na EJA é majoritariamente desenvolvido de forma simplificada. Deste modo, a proposta para a pesquisa seria abordar conceitos de cinemática escalar. A tabela 1 apresenta, resumidamente, os conteúdos que foram trabalhados:

\begin{tabular}{|c|l|c|}
\hline Módulo & Conteúdo & Carga horária \\
\hline Módulo 1 & $\begin{array}{l}\text { Conceitos iniciais: Referencial, Trajetória, } \\
\text { Movimento e Repouso. }\end{array}$ & 100 Min \\
\hline Módulo 2 & $\begin{array}{l}\text { Velocidade escalar média, instantânea e Mo- } \\
\text { vimento Retilíneo Uniforme. }\end{array}$ & 100 Min \\
\hline Módulo 3 & $\begin{array}{l}\text { Aceleração escalar média, tipos de acelera- } \\
\text { ção e Movimento Retilíneo Uniformemente } \\
\text { Variado. }\end{array}$ & 100 \\
\hline
\end{tabular}

Tabela 1: : Organização dos Conteúdos. Fonte: Própria do autor (2019).

Para cada módulo apresentado na tabela 1 , foi executado um teste conceitual ${ }^{2}$ contendo 4 ou 5 questões conceituais, organizados como mostra a tabela 2.

\begin{tabular}{|c|c|l|c|}
\hline SIGLA & TESTE CONCEITUAL & CONTEÚDO ABORDADO & No. DE QUESTÕES \\
\hline TC1 & TESTE CONCEITUAL 01 & $\begin{array}{l}\text { Conceitos iniciais: Referen- } \\
\text { cial, Trajetória, Movimento e } \\
\text { Repouso. }\end{array}$ & 5 \\
\hline TC2 & TESTE CONCEITUAL 02 & $\begin{array}{l}\text { Velocidade escalar média, ins- } \\
\text { tantânea e Movimento Retilí- } \\
\text { neo Uniforme. }\end{array}$ & 5 \\
\hline TC3 & TESTE CONCEITUAL 03 & $\begin{array}{l}\text { Aceleração escalar média, ti- } \\
\text { pos de aceleração e Movi- } \\
\text { mento Retilíneo Uniforme- } \\
\text { mente Variado. }\end{array}$ & \\
\hline
\end{tabular}

Tabela 2: Organização dos testes conceituais para a metodologia PI. Fonte: Própria do Autor (2019)

\footnotetext{
${ }^{2}$ Teste conceituais e de Leitura estão disponíveis no Apêndice A.
} 
Para comparar as turmas $P_{1}$ e $P_{2}$, em que houve o uso da metodologia IpC, com a turma $T_{1}$ na qual houve aplicação da metodologia tradicional, utilizaram-se pré e pós-testes formulados a partir de questões de vestibulares e do ENEM. Esses testes foram aplicados no início da pesquisa, quando ainda não havia sido desenvolvido o conteúdo, e ao fim da mesma, momento no qual o conteúdo já havia sido estudado integralmente. Para que fosse comparado os resultados desse trabalho com outros executados a partir da mesma metodologia, os dados foram analisados utilizando o ganho normalizado de Hake.

\section{Análise dos Resultados}

\section{V.1. Ganho normalizado de Hake}

Para fins de análise, utilizou-se o ganho de Hake para comparar os resultados entre pré e pós-testes.

O ganho normalizado, ou ganho de Hake, é um parâmetro de avaliação que mede a evolução do aprendizado de uma turma de estudantes por um determinado método de ensino, de maneira quantitativa, através de uma análise da porcentagem de acertos em dois testes.

(DINIZ, 2015, p. 37)

Richard R. Hake, professor do departamento de Física da Universidade de Indiana, realizou a análise de dados referentes a pré e pós-testes de dados recolhidos em várias instituições de ensino, como escolas secundárias, faculdades e universidades.

No total, foram avaliados 62 cursos de Física introdutória. A finalidade principal dessa investigação era avaliar o entendimento conceitual que cada curso proporcionava aos estudantes. Para realizar esse estudo, utilizou-se o ganho normalizado, ou como é mais conhecido, ganho de Hake, definido como a razão entre o ganho médio real \%G=(\% [pós] -\% [pré]) e o ganho médio máximo possível \%GM=(100\% -\% [pré]), matematicamente expresso como (Hake, 1998):

$$
\langle g\rangle=\frac{\%\langle G\rangle}{\%\left\langle G_{M}\right\rangle}
$$

Para fins de pesquisa, Hake (1998) define:

a) "Envolvimento interativo", (EI): métodos concebidos, pelo menos em parte, para promover a compreensão conceitual por meio do engajamento interativo dos alunos em atividades de participação e de hands-on (geralmente) que geram feedback imediato por meio de discussões com pares e/ou instrutores, todos julgados por suas descrições de literatura;

b) Cursos "tradicionais"(T) como aqueles relatados pelos instrutores para fazer pouco ou nenhum uso de métodos de IE, contando principalmente com palestras de estudantes passivos, laboratórios de receitas e exames de problema algorítmico; 
c) Cursos de Engajamento Interativo (EI), como os relatados por instrutores para fazer uso substancial de métodos de IE;

d) Ganho normalizado médio <g> para um curso com o rácio do ganho médio real $<\mathrm{G}>$ para o máximo possível ganho médio, ou seja

$$
\langle g\rangle=\frac{\%\langle G\rangle}{\%\left\langle G_{M}\right\rangle}=\%\left\langle S_{f}\right\rangle-\%\left\langle S_{i}\right\rangle 100 \%-\%\left\langle S_{i}\right\rangle,
$$

onde $\left\langle S_{f}\right\rangle$ e $\left\langle S_{i}\right\rangle$ são as médias inicial e final da turma;

e) Cursos de "alto ganho"são aqueles com $g \geq 0,7$;

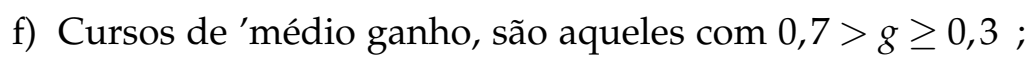

g) Cursos de baixo ganho são aqueles com $g<0,3$.

\section{V.2. Contraste entre os ganhos de Hake para o teste conceitual 01}

Aqui é realizada uma análise do ganho de Hake para cada questão conceitual. Sabe-se que o ganho normalizado de Hake avalia o ganho para pré/pós-testes. Entretanto, este foi aplicado às questões conceituais com a finalidade de verificar o desempenho de cada turma durante a aplicação da metodologia IpC.

A tabela 3 exibe os resultados obtidos para o ganho de Hake para cada uma das questões abordadas no teste conceitual 01. A partir desses resultados, em termos estatísticos, atingiu-se, neste teste conceitual, alto ganho para ambas as turmas. No entanto, em algumas questões, $Q_{2}$ e $Q_{4}$, a turma $T_{2}$ atingiu resultados abaixo do esperado. Esse resultado partiu da turma na qual as dificuldades apresentadas durante as aulas foram maiores, refletindo, consequentemente, em resultados pouco expressivos

Por outro lado, a turma $T_{1}$ teve desempenho satisfatório durante toda a aplicação do teste conceitual 01.

\begin{tabular}{|l|c|c|c|c|c|c|}
\hline & $Q_{1}$ & $Q_{2}$ & $Q_{3}$ & $Q_{4}$ & $Q_{5}$ & Média \\
\hline TURMA $T_{1}$ & 0,76 & 0,7 & 0,78 & 0,92 & 1 & 0,79 \\
\hline TURMA $T_{2}$ & 1 & 0,58 & 0,91 & 0,5 & 0,73 & 0,74 \\
\hline
\end{tabular}

Tabela 3: Contraste entre os Ganhos de Hake para o teste conceitual 01. Fonte: Própria do Autor (2019)

Os resultados para a turma $T_{1}$ em todas as questões determinou um ganho de Hake acima de 0,7 , o que denota ganho significativo, do ponto de vista da metodologia Peer Instruction, o que já era esperado, uma vez que essa turma já possuía maior facilidade no desempenho das atividades e na compreensão dos conteúdos.

\section{V.3. Contraste entre os ganhos de Hake para o teste conceitual 02}

Uma das definições da metodologia PI se dá a partir do percentual de acertos acima de $70 \%$. Isso demonstra que a maior parte da turma já desenvolveu, de forma prévia, os conceitos abordados. Dentro dos testes conceituais abordados neste trabalho, o teste conceitual 02 , neste sentido, apresentou melhor desenvolvimento, principalmente quando 
considerados os resultados apresentados pela turma $P_{1}$, que obteve desempenho acima de $70 \%$ em 3 das 5 questões tratadas. Esse resultado expressa uma aprendizagem significativa para essa turma, quando utilizada a metodologia PI.

\begin{tabular}{|l|c|c|c|c|c|c|}
\hline & $Q_{1}$ & $Q_{2}$ & $Q_{3}$ & $Q_{4}$ & $Q_{5}$ & Média \\
\hline TURMA $P_{1}$ & 0,4 & $\mathrm{X}$ & $\mathrm{X}$ & 0,62 & $\mathrm{X}$ & 0,51 \\
\hline TURMA $P_{2}$ & 0,95 & 0,8 & 0,6 & 0,82 & $\mathrm{X}$ & 0,79 \\
\hline
\end{tabular}

Tabela 4: Contraste entre os Ganhos de Hake para o teste conceitual 02. Fonte: Própria do Autor (2019)

A turma $P_{2}$, apesar de ter apenas a questão 05 com a média de acertos acima de $70 \%$, ou seja, dispensada da discussão em turma, obteve desempenho médio satisfatório, apresentando uma média de acertos que possibilitou um ganho de Hake de 0,79, em média, ou seja, a turma obteve alto ganho.

É importante observar que a média entre os ganhos da turma $T_{1}$, na tabela 4 é de 0,51. Entretanto, essa média não levou em consideração as questões 2, 3 e 5, que foram dispensadas da IpC.

\section{V.4. Contraste entre os ganhos de Hake para o teste conceitual 03}

As questões do teste conceitual 03, que versavam sobre aceleração escalar média, instantânea e movimento uniformemente variado, têm os resultados apresentados na tabela 5. A partir desta tabela, verificou-se que o desempenho da turma $P_{1}$ não proporcionou ganhos significativos; na questão 04 houve ganho nulo, ou seja, não tendo havido melhora significativa no desempenho da turma. Por outro lado, na questão 03, a turma apresentou resultado satisfatório acima de $70 \%$.

\begin{tabular}{|c|c|c|c|c|c|}
\hline & $Q_{1}$ & $Q_{2}$ & $Q_{3}$ & $Q_{4}$ & Média \\
\hline TURMA $P_{1}$ & 1 & 0,67 & $X$ & 0 & 0,56 \\
\hline TURMA $P_{2}$ & 0,23 & 0,83 & 0,83 & 0,94 & 0,71 \\
\hline
\end{tabular}

Tabela 5: Contraste entre os Ganhos de Hake para o teste conceitual 03. Fonte: Própria do Autor (2019)

Ao se comparar os resultados das duas turmas, verifica-se que, em média, a turma $P_{2}$ obteve resultados acima de 0,7 . Desse modo, seu desempenho pode ser analisado com alto ganho, observando que apenas na questão 01 essa turma obteve um resultado muito baixo, caracterizando um conceito que pode ser um pouco melhor abordado. Em contrapartida, a turma $P_{1}$ apresentou alguns resultados ruins, como foi comentado acima com relação à questão 04 , mas obteve ganho de Hake máximo na questão 1, e em média teve ganho de Hake de 0,56 que indica ganho médio.

\section{ANÁLISE de PRÉ TESTE E PÓs TESTE}

A utilização de pré e pós-testes ${ }^{3}$ tem como finalidade verificar os ganhos de aprendizagens, significativos ou não, alcançados após aplicação de metodologias de ensino ou

\footnotetext{
${ }^{3}$ As questões utilizadas nos pré e pós testes estão no apêndice A.
} 
métodos tradicionais. Na presente pesquisa, foram utilizados pré e pós-testes iguais, que abordavam problemas do ENEM e vestibulares envolvendo o conteúdo de cinemática. No total, havia 13 problemas. Durante esta pesquisa, os testes foram aplicados em três turmas, $P_{1}$ e $P_{2}$, que são as turmas em que ocorreu a aplicação da metodologia PI e a turma $T_{1}$, na qual foi aplicada a metodologia tradicional, ou seja, sem engajamento interativo.

\section{VI.1. Resultados: turmas PI versus turma tradicional}

Este trabalho teve como principal objetivo abordar os conhecimentos em cinemática escalar utilizando a metodologia Peer Instruction. Para isso, fez-se necessário a aplicação da metodologia em duas turmas que teriam seus resultados comparados com outra turma na qual foi utilizada a metodologia tradicional de ensino. Com intuito de avaliar as turmas por meio do ganho de Hake, foram aplicados pré/pós-testes, cujos resultados estão apresentados na tabela 6.

\begin{tabular}{|l|l|l|l|l|l|}
\hline \multicolumn{5}{|c|}{ METODOLOGIA PI } & \multirow{2}{*}{ GANHOS } \\
\hline & TURMA $P_{1}$ & $17 \%$ & $36 \%$ & 0,23 & baixo ganho \\
\hline & TURMA $P_{2}$ & $23 \%$ & $46 \%$ & 0,27 & baixo ganho \\
\hline
\end{tabular}

Para turma $P_{1}$, como mostra a tabela 6 , o resultado da média percentual de acertos da turma chegou a $17 \%$ para o pré-teste e $36 \%$ para o pós-teste. Portanto, o resultado encontrado para o ganho significativo de aprendizagem, como definido por Hake (1998), foi de baixo ganho, ou seja, apresentou um valor para o ganho de Hake abaixo de 0,3.

A turma $P_{2}$ obteve resultados estatísticos um pouco mais expressivos que a turma $P_{1}$, alcançando, no pré-teste $23 \%$ no desempenho geral da turma, e $43 \%$ na aplicação do pósteste. Esses valores percentuais obtidos através dos testes possibilitou o cálculo do ganho de Hake de 0,27, que corresponde a um valor abaixo de 0,3 que, como já referido neste artigo, determina baixo ganho de aprendizagem.

Na metodologia tradicional, aplicada na turma $T_{1}$, os resultados foram ainda menos significativos. Na aplicação do pré e pós-testes, a turma $T_{1}$ atingiu um percentual de $26 \%$ inicialmente, e alcançou, no pós-teste, apenas $29 \%$, ou seja, seu ganho de Hake para esse teste atingiu o valor de 0,04 e caracterizou também, baixo ganho. Além disso, considerando os ganhos de Hake (1998), os valores para aulas tradicionais variam entre 0,1 e 0,2 enquanto que para turmas onde são utilizados engajamento interativo temos um intervalo entre 0,48 e 0,7, Mazur em A Revolução da Aprendizagem Ativa determinou que para Peer Instruction os ganhos de Hake devem apresentar valores maiores que 0,36.

As metodologias que foram aplicadas às três turmas nos conduziram, todas, a baixos ganhos de aprendizagem, seja a metodologia com engajamento interativo ou metodologia tradicional.

\section{VI.2. Comparando os resultados com outras literaturas}

Foram selecionados três trabalhos no âmbito nacional que utilizaram a Peer Instruction como metodologia de ensino e que adotaram uma avaliação da aprendizagem a partir do 
ganho normalizado de Hake. Essa seção tem como finalidade apresentar um breve confronto entre os resultados encontrados neste trabalho e os trabalhos antepostos.

Entre os trabalhos elegidos, aqueles de Araújo et al (2017) apresentaram os melhores resultados. Na tabela 7 foram colocados os resultados obtidos para o ganho de Hake para duas turmas (o menor e o maior valor encontrados). Como já descrito neste artigo, considera-se ganho significativo quando os valores estão entre 0,48 e 0,7.

A turma TA atingiu ganho de Hake no valor de 0,12 , valor esse que é definido por Hake como baixo ganho. Por outro lado, a turma TI teve como resultado um valor de 0,37 para o ganho de Hake, ou seja, ganho médio. Oliveira (2015), ao utilizar o engajamento interativo, aplicando a metodologia Peer Instruction em conjunto com a Just in Time Teaching (JiTT), obteve resultados com baixo ganho para a aprendizagem, como mostra a tabela 7; o resultado encontrado alcançou o valor de 0,17 .

Dentre os trabalhos relacionados anteriormente, o de Diniz (2015) foi o que apresentou o menor ganho após aplicação da metodologia PI. Neste, obteve-se como ganho de Hake o valor de 0,1 , que se pode definir como baixo ganho.

Analisando os valores da tabela 7 nota-se que, comparado com os resultados nacionais descritos, esta presente pesquisa encontrou valores para o ganho de Hake, em turmas nas quais foram aplicadas a metodologia PI, entre 0,23 e 0,27. Assim, como a maior parte das turmas supracitadas, também apresentou baixo ganho.

Tais resultados são considerados pouco significativos do ponto de vista da literatura internacional. Hake determina que, para metodologias com engajamento interativo, os valores para o ganho de Hake estejam entre 0,48 e 0,7. Assim como descrito acima, Mazur aponta que, para esse mesmo caso, a aplicação significativa do Peer Instruction apresenta um ganho de 0,36 .

Todavia, do ponto de vista da literatura nacional, os valores para este ganho podem ser considerados significativos, uma vez que os mesmos superaram os valores para a metodologia tradicional e também obtiveram valores que ultrapassaram alguns dos trabalhos descritos. Isso denota que a aplicação do método PI, uma vez aplicado com eficácia, pode nos remeter a resultados potencialmente significativos.

\begin{tabular}{|c|c|c|c|c|c|}
\hline PESQUISADORES & \multicolumn{4}{|c|}{ METODOLOGIA PI } & GANHOS \\
\hline & TURMAS & Pré Teste (\%) & Pós Teste (\%) & Média & \\
\hline \multirow{2}{*}{ ARAÚJO et al. (2017) } & TA & 29,4 & 37,8 & 0,12 & Baixo ganho \\
\cline { 2 - 6 } & TI & 29,7 & 55,7 & 0,37 & Ganho médio \\
\hline OLIVEIRA (2015) & T04 & 29 & 41 & 0,17 & Baixo ganho \\
\hline DINIZ (2015) & T03 & 24,5 & 32,3 & 0,1 & Baixo ganho \\
\hline & TURMA P1 & 17 & 36 & 0,23 & Baixo ganho \\
\cline { 2 - 6 } & TURMA P2 & 23 & 43 & 0,27 & Baixo ganho \\
\hline
\end{tabular}

Tabela 6: Confronto dos resultados com outros trabalhos. Própria do Autor (2019) 


\section{CONSIDERAÇÕES FINAIS}

Os resultados encontrados em outras literaturas nacionais, como, por exemplo, os citados na tabela 7, indicam que a metodologia Peer Instruction ainda precisa ser satisfatoriamente implementada nas escolas brasileiras. Araújo et al (2017) aplicou a metodologia em sete turmas e, entre elas, apenas 3 obtiveram valores para o ganho de Hake acima de 0,3 . Por outro lado, Diniz (2015) e Oliveira (2015) não alcançaram resultados significativos, quando comparados com os resultados internacionais de Hake e Mazur.

A metodologia aplicada às turmas de $1 \nmid$ série do Ensino Médio da EJA tiveram resultados que, comparados às literaturas internacionais, que apresentam valores entre 0,36 e 0,7, mostram-se muito abaixo do esperado. Os valores para o ganho de Hake obtidos nesta pesquisa, utilizando a metodologia PI, são de 0,23 e 0,27 , para as turmas $P_{1}$ e $P_{2}$, resultado este que se apresenta significativo ao compararmos com as literaturas nacionais como, por exemplo, Oliveira (2015) e Diniz (2015) e ao confrontar com algumas turmas verificadas por Araújo et al (2017), relativamente à qual também exibe uma diferença considerável.

Vale ressaltar que a presente pesquisa realizou atividades e testes de leitura visando melhor assimilação de conteúdo pelos alunos. No entanto, de modo geral, as atividades não apresentaram resultados expressivos o que indica que o desenvolvimento de atividades de leituras mais efetivas pode nos conduzir a resultados melhores.

Embora os resultados do pré e pós-testes não tenham um ganho de Hake de acordo com as literaturas internacionais, quando comparados com as pesquisas nacionais, a metodologia Peer Instruction mostra-se uma ferramenta interessante para obter uma aprendizagem potencialmente significativa, pois ela permite que sejam empregadas questões conceituais que demonstraram resultados de grande relevância e com ganhos de Hake acima da média das literaturas nacionais.

A partir dos resultados apresentados por Mazur e Hake, é notável que ao longo dos anos as literaturas nacionais tenham apresentado valores de baixos ganhos, o que indica que ainda é necessária grande evolução na aplicação da metodologia PI no Brasil.

\section{REFERÊNCIAS}

ARAÚJO et. al; Uma associação do método Peer Instruction com circuitos elétricos em contextos de aprendizagem ativa; Revista Brasileira de Ensino de Física, vol. 39, nž 2, 2017.

OLIVEIRA. Zaquel. A utilização da metodologia da Instrução pelos Colegas na aprendizagem do conceito de força em turmas das áreas de ciências exatas e engenharia. Universidade Federal de Itajubá, 2015.

HAKE, R. Interactive - engagement vs. traditional methods: A six thousand student survey of mechanics test data for introductory physics courses. American Journal of Physics. AAPT, v. 66, n. 1, p. 64-74, 1998.

DINIZ. Allan. Implementação Do Método Peer Instruction Em Aulas De Física No Ensino Médio. Universidade Federal de Viçosa, Programa de Pós-Graduação do Mestrado Nacional Profis- 
sional em Ensino de Física, Viçosa MG, 2015.

MAZUR, E. Peer Instruction: A Revolução da Aprendizagem Ativa. Penso, Porto Alegre 2015, 1a ed.

MAZUR, E. Peer Instruction: A Users Manual, Prentice Hall, Upper Saddle River, NJ, (1997). 
O ensino de cinemática apoiado na metodologia peer instruction para...

A. Testes Conceituais 


\section{Teste Conceitual 01}

1. (UFB) Um pássaro está voando e se afastando de uma árvore. Em relação ao pássaro, a árvore está em repouso ou em movimento?
a) Em movimento;
b) Em repouso;
c) Não é possível definir;
d) Em movimento em relação a Terra e repouso em relação ao pássaro;

2. Você está viajando, sentado na poltrona de um ônibus, pela BR-174, indo em direção a Pr. Figueiredo. Marque a alternativa que mostra um referencial ao qual você está em repouso e outro referencial em relação ao qual você está em movimento, respectivamente.
a) árvores e motorista do ônibus
b) solo do ônibus e a porta do ônibus
c) casas e semáforos
d) janela do ônibus e árvores
e) postes elétricos e meio fio

3. Um aluno, ao ler este problema, está sentado em uma cadeira. O aluno está em repouso ou em movimento?
a) Em repouso
b) Em movimento
c) Depende do referencial adotado
d) É impossível definir
e) Depende do estado emocional do aluno

4. (UFMG) Observe esta figura.

Daniel está andando de skate em uma pista horizontal.

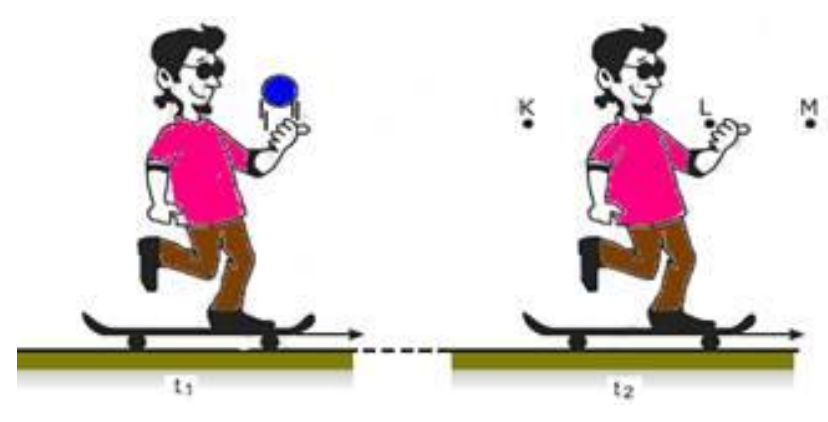

No instante $\mathrm{t}_{1}$, ele lança uma bola, que, sobe verticalmente. A bola sobe alguns metros e cai, enquanto Daniel continua a se 
mover em trajetória retilínea, com velocidade constante. No instante $\mathrm{t}_{2}$, a bola à mesma altura de que foi lançada. Despreze os efeitos da resistência do ar.

Assim sendo, no instante $t_{2}$, o ponto em que a bola estará, mais provavelmente é:

a) $\mathrm{K}$

b) $\mathbf{L}$

c) $\mathrm{M}$

d) qualquer um, dependendo da velocidade de lançamento.

5. (UESB-BA) Um avião, voando com velocidade constante e próximo à superfície da Terra, abandona um objeto. Despreze o efeito do ar.

Para um observador parado no solo, a trajetória do objeto é:

a) vertical.

b) oblíqua.

c) semicircular.

d) hiperbólica.

e) parabólica. 


\section{Teste conceitual 02}

1. O gráfico abaixo apresenta a variação do espaço de um automóvel que percorre uma estrada durante determinado tempo, o eixo vertical (ordenadas) apresenta os valores do espaço percorrido, o eixo horizontal (abscissa) mostra os valores para o tempo. O que podemos afirmar sobre a posição inicial desse automóvel?
a) O carro encontra-se na posição de $300 \mathrm{~m}$;
b) O carro encontra-se na posição de $200 \mathrm{~m}$;
c) O carro encontra-se na posição de $0 \mathrm{~m}$;
d) $\mathbf{O}$ carro encontra-se na posição de 100;

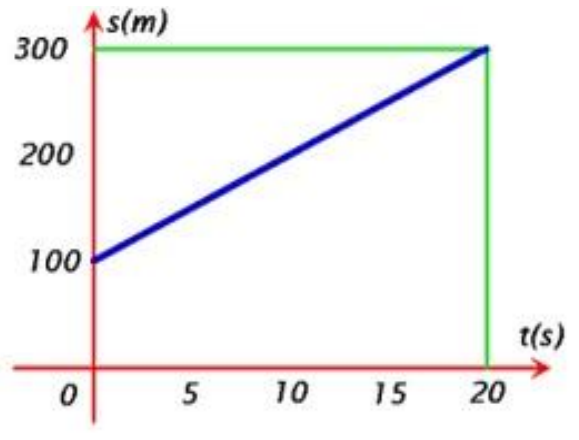

2. Um trem que se move ao longo de um trilho reto e longo. O gráfico mostra a velocidade como função do tempo. O gráfico mostra que o trem:
a) Acelera o tempo todo;
b) Freia o tempo todo;
c) Acelera em uma parte e freia em outra parte;
d) Se move com velocidade constante;

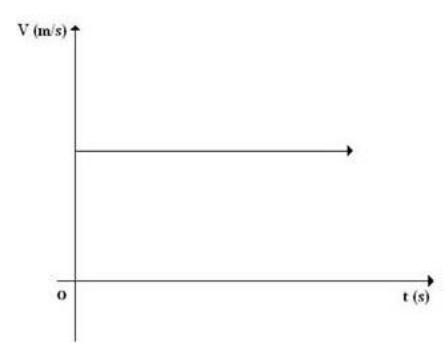

3. Uma pessoa caminha sobre uma estrada reta e plana, com velocidade constante. Ao passar pela marca de $5 \mathrm{~km}$, seu relógio marca $1 \mathrm{~h}$. Quando seu relógio marca $3 \mathrm{~h}$, ela se encontra na marca de $9 \mathrm{~km}$. Qual o valor do módulo de sua velocidade?
a) $2 \mathrm{~km} / \mathrm{h}$
b) $3 \mathrm{~km} / \mathrm{h}$
c) $5 \mathrm{~km} / \mathrm{h}$
d) $4,5 \mathrm{~km} / \mathrm{h}$

4. Se a velocidade média, de um automóvel, de São Paulo ao Rio de Janeiro foi de 80 $\mathrm{km} / \mathrm{h}$, isto significa que:

a) em todos os instantes o automóvel manteve $80 \mathrm{~km} / \mathrm{h}$; 

b) nunca a velocidade foi superior a $80 \mathrm{~km} / \mathrm{h}$;
c) nunca a velocidade foi inferior a $80 \mathrm{~km} / \mathrm{h}$;
d) se mantiver a velocidade de $80 \mathrm{~km} / \mathrm{h}$, em todo o trajeto, teria feito o mesmo percurso, no mesmo período;

5. Você está sentado na poltrona do passageiro de um taxi, e consegue ver nitidamente o velocímetro do carro durante a viagem. Durante todo o percurso que o motorista de taxi faz é possível verificar:
a) A velocidade média do percurso;
b) A aceleração média do percurso;
c) A Velocidade instantânea do carro;
d) Aceleração Instantânea do carro; 
Revista do Professor de Física, v. 3, n. 3, p. 76-104, Brasília, 2019.

B. Testes de leitura 


\section{Teste de Leitura 01}

\section{OBS: As alternativas corretas estão em negrito}

1. Sobre o movimento de um corpo ou objeto, é correto afirmar:
a) Ele depende de uma referência;
b) Em qualquer caso é possível determinar movimento e repouso;
c) Sempre se considera um referencial na Terra para observar um movimento;
d) É uma grandeza física não definida corretamente;

2. Analise a frase a seguir: "Vemos então que para um mesmo evento simultâneo as condições de movimento e repouso são relativas e dependem de quem as observa.“. Está frase é correspondente a dizer que:
a) Movimento e repouso não dependem de um referencial;
b) Movimento e repouso dependem de um referencial;
c) Só existe um único referencial válido;
d) Movimento e repouso dependem de um referencial fixo na Terra;

3. Você está deitado sobre sua cama, para um observador no Sol você está:
a) Parado;
b) Se movimentando na vertical;
c) Está em Movimento;
d) Não é possível afirmar nada.

4. Considere um ônibus com velocidade de $40 \mathrm{~km} / \mathrm{h}$ em uma avenida da Cidade de Manaus. Marque a alternativa abaixo que descreve uma afirmação CORRETA, de acordo com a leitura do material:
a) Todos, ônibus e passageiros estão em movimento;
b) Os passageiros estão em repouso em relação a um passageiro externo ao ônibus;
c) Os passageiros estão em movimento em relação ao motorista;
d) Os passageiros estão em repouso em relação ao motorista; 


\section{Teste de Leitura 02}

1. Como é chamado o Movimento onde há variação de Velocidade?
a) Movimento Retilíneo Uniforme
b) Movimento Retilíneo Uniformemente Variado;
c) Movimento circular;
d) Movimento Uniforme;

2. Qual o tipo de movimento descrito a seguir: "O valor da aceleração possui sempre o mesmo sinal da velocidade logo: o valor do módulo da velocidade deve ser crescente."
a) Acelerado;
b) Desacelerado;
c) Retardado;
d) Retrógrado;

3. Qual o tipo de movimento descrito a seguir: "O valor da aceleração possui sempre sinal contrário ao da velocidade assim: o valor do módulo da velocidade deve ser decrescente."
a) Acelerado;
b) Desacelerado;
c) Retardado;
d) Retrógrado; 


\section{Teste de Leitura 03}

1. Como é chamado o movimento no qual a velocidade é constante?
a) Movimento Retilíneo Uniforme;
b) Movimento Uniformemente Variado;
c) Movimento Linear;
d) Movimento em Queda Livre;

2. Qual das relações abaixo demonstra corretamente o cálculo da velocidade média?
a) Divisão entre o Espaço percorrido e o tempo;
b) Divisão entre o Tempo e Espaço percorrido;
c) Soma entre o tempo e a distância percorrida;
d) Multiplicação do tempo pelo Espaço percorrido;

3. Marque o gráfico abaixo que representa corretamente a velocidade média no Movimento Retilíneo Uniforme:

a)

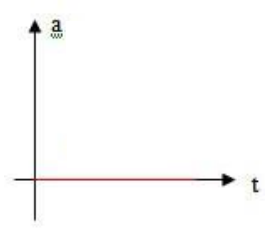

b)

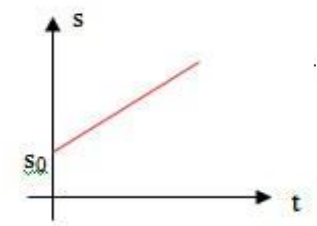

c)

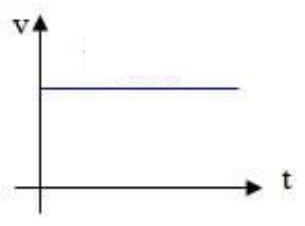

d)

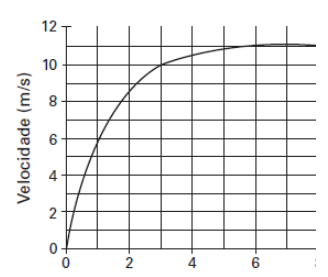

4. A partir do conceito de velocidade instantânea, marque a alternativa correta:

a) Corresponde a velocidade de um carro em determinado instante de tempo; 
b) Corresponde a velocidade de um carro ao longo de um deslocamento;

c) Corresponde a soma das velocidades em instantes de tempos diferentes;

d) Corresponde a variação da velocidade em um determinado intervalo de tempo; 
O ensino de cinemática apoiado na metodologia peer instruction para...

C. Pré e Pós-testes 


\section{Pré/Pós-Testes}

1. (PUC-SP) A afirmação "todo movimento é relativo" significa que:

Todos os cálculos de velocidade são imprecisos.

b) Não existe movimento com velocidade constante.

c) A velocidade depende sempre de uma força.

d) A velocidade depende sempre de uma aceleração.

e) A descrição de qualquer movimento requer um referencial.

2. (UEPB) Um professor de física verificando em sala de aula que todos os seus alunos se encontram sentados, passou a fazer algumas afirmações para que eles refletissem e recordassem alguns conceitos sobre movimento.

Das afirmações seguintes formuladas pelo professor, a única correta é:

a) Pedro (aluno da sala) está em repouso em relação aos demais colegas, mas todos nós estamos em movimento em relação à Terra.

b) Mesmo para mim (professor), que não paro de andar, seria possível achar um referencial em relação ao qual eu estivesse em repouso.

c) A velocidade dos alunos que eu consigo observar agora, sentados em seus lugares, é nula para qualquer observador humano.

d) Como não há repouso absoluto, nenhum de nós está em repouso, em relação a nenhum referencial.

e) O Sol está em repouso em relação a qualquer referencial.

3. (UFMG) Júlia está andando de bicicleta com velocidade constante, quando deixa cair uma moeda. Tomás está parado na rua e vê a moeda cair. Considere desprezível a resistência do ar. Assinale a alternativa em que melhor estão representadas as trajetórias da moeda, como observadas por Júlia e por Tomás.
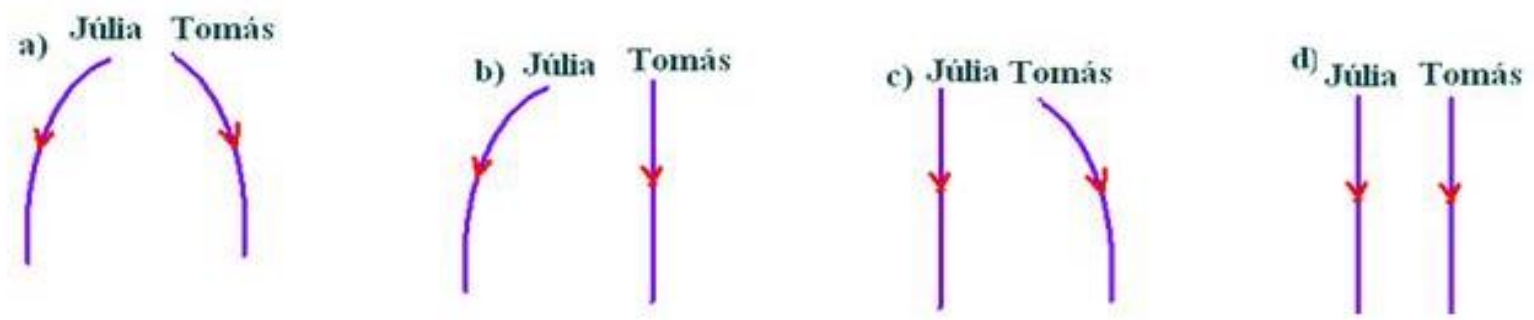

4. (ENEM 2013) Conta-se que um curioso incidente aconteceu durante a Primeira Guerra Mundial. Quando voava a uma altitude de dois mil metros, um piloto francês viu o que acreditava ser uma mosca parada perto de sua face. Apanhando-a rapidamente, ficou surpreso ao verificar que se tratava de um projétil alemão.

PERELMAN, J. Aprenda física brincando. São Paulo: Hemus, 1970.

O piloto consegue apanhar o projétil, pois

a) Ele foi disparado em direção ao avião francês, freado pelo ar e parou justamente na frente do piloto. 
b) O avião se movia no mesmo sentido que o dele, com velocidade visivelmente superior.

c) Ele foi disparado para cima com velocidade constante, no instante em que o avião francês passou.

d) O avião se movia no sentido oposto ao dele, com velocidade de mesmo valor.

e) O avião se movia no mesmo sentido que o dele, com velocidade de mesmo valor.

5. Em uma prova de $100 \mathrm{~m}$ rasos, o desempenho típico de um corredor padrão é representado pelo gráfico a seguir:

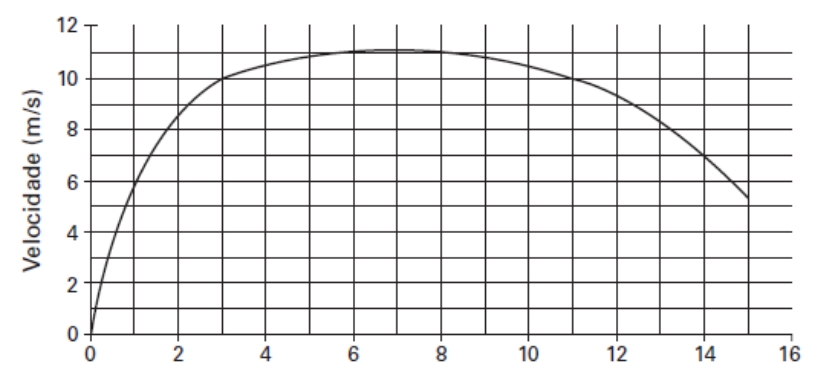

Baseado no gráfico, vxt, em que instante de tempo a velocidade do corredor é $10 \mathrm{~m} / \mathbf{s}$ ?
a) 2 segundos.
b) 5 segundos.
c) 3 segundos.
d) 11 segundos.
e) 15 segundos.

6. (UFPA) Maria saiu de Mosqueiro às 6 horas e 30 minutos, de um ponto da estrada onde o marco quilométrico indicava $\mathrm{km}$ 60. Ela chegou a Belém às 7 horas e 30 minutos, onde o marco quilométrico da estrada indicava $\mathrm{km} 0$. A velocidade média, em quilômetros por hora, do carro de Maria, em sua viagem de Mosqueiro até Belém, foi de:
a) 45
b) 55
c) 60
d) 80
e) 120

7. (PUC-RS) A velocidade escalar no movimento uniforme é:
a) constante
b) variável.
c) constante em módulo, mas de sinal variável.
d) sempre positiva.
e) sempre negativa.

8. (F.E. Edson Queiroz-CE) Sendo a distância entre Fortaleza e Maranguape igual a $40 \mathrm{~km}$ e considerando a velocidade máxima permitida de $80 \mathrm{~km} / \mathrm{h}$, o tempo mínimo que se deve gastar na viagem, em trânsito completamente livre, é:
a) $15 \mathrm{~min}$
b) $30 \mathrm{~min}$ 

c) $24 \mathrm{~min}$
d) $80 \mathrm{~min}$

9. A imagem abaixo mostra o velocímetro de um automóvel com a marcação da velocidade em vários momentos, em relação as velocidades marcadas nesta imagem, marque a alternativa CORRETA:
a) São os valores de velocidade instantâneas do automóvel;
b) São os valores das velocidades médias do automóvel;
c) São os valores das acelerações médias de um automóvel;
d) A imagem apresenta a aceleração instantânea do automóvel;

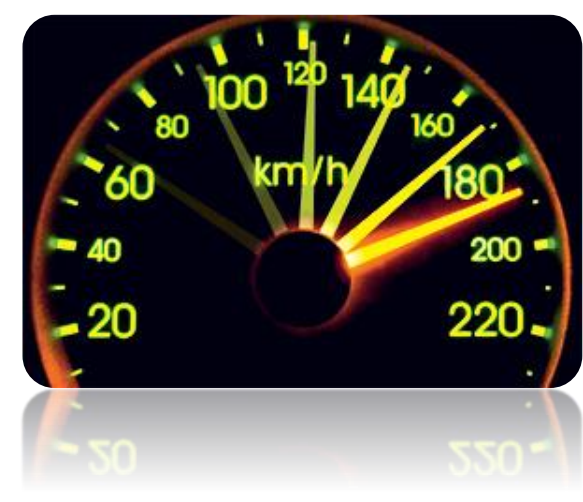

10. De acordo com o conteúdo abordado em sala de aula, marque a alternativa que apresenta a melhor definição para a velocidade instantânea de um automóvel:
a) É a aceleração medida em um determinado momento;
b) É a velocidade medida em um determinado deslocamento;
c) É a velocidade medida quando a velocidade é constante;
d) É a velocidade medida em um determinado momento; 